\title{
Introducción Matrimonio en los siglos XVI-XVIII: derecho canónico, conflictos y realidad social
}

\author{
Ana de Zaballa Beascoechea \\ Universidad del País Vasco UPV/EHU \\ ana.dezaballa@ehu.eus
}

La elaboración de este dossier está estrechamente relacionado con el Proyecto de Investigación Justicia eclesiástica y conformación de la sociedad en la América Hispana colonial ${ }^{1}$, dentro del cual nos propusimos estudiar el matrimonio y las costumbres o trasgresiones relacionadas con él como un elemento clave y novedoso para entender las dinámicas sociales, así como la comparativa entre diferentes regiones y grupos sociales. Tres autoras del dossier pertenecemos a este grupo y otros dos trabajan temas paralelos desde sus propios proyectos ${ }^{2}$.

Con estas investigaciones, que abarcan los tres siglos de la Edad Moderna, se ha profundizado en la práctica del matrimonio postridentino ${ }^{3}$ en ambos virreinatos, tanto entre la población indígena como española y de castas; se ha tratado sobre matrimonios secretos, divorcios y nulidades, matrimonios mestizos, la publicidad y su forma canónica, así como la normativa y las variantes de su aplicación en Indias, tema de gran interés en la historiografía actual ${ }^{4}$.

Los cinco trabajos que tengo el gusto de presentar se mueven entre dos intereses, la normativa canónica por una parte y sus consecuencias en la realidad social tanto en la península como en sus territorios americanos por otra. Estos trabajos, que abarcan los tres siglos coloniales, suponen, por tanto, un buen ejemplo de los problemas en torno al matrimonio en ambos lados del Atlántico.

El orden jurídico canónico no se trasladó sin más a Indias, sino que existió un complejo proceso de recepción de este derecho que pasó por su modificación para adaptarse a las nuevas necesidades, hasta la elaboración de la juridicidad propia de las Indias 5 . El derecho canónico y la práctica judicial, presentes en estas investigaciones a través de los expedientes judiciales, los sínodos, concilios y otras normatividades

1 Proyecto Justicia eclesiástica y conformación de la sociedad en la América Hispana colonial, HAR201235197, del Ministerio de Economía y Competitividad. Investigadora Principal Ana de Zaballa Beascoechea.

2 Proyectos Las mujeres y las emociones en Europa y América. Siglos XVII-XIX, HAR2012-37394; La vida emocional de las mujeres: experiencias del mundo, formas de la sensibilidad. Europa y América, 16001900. HAR2015/63804-P.

3 Otras publicaciones del Proyecto en este sentido en: Traslosheros, 2016; LATASA, 2016; RAmos 2016; ZABALLA, 2016.

4 Traslosheros - Zaballa 2010, Latasa 2008, Albani - Barbosa - Duve (en prensa).

5 Traslosheros 2014, p. 4. 
eclesiásticas son merecedores de atención porque permiten conocer la sociedad a la cual pertenecieron. Dentro de la variedad de temáticas en torno al matrimonio que abordan estas investigaciones, el derecho canónico estará en el eje: en la defensa de la publicidad en unos, o en los procedimientos de demandas y solicitudes contra sus obligaciones en otros.

El precepto de publicidad establecido en Trento afectará a tres de las investigaciones desde diferentes perspectivas. Latasa analizará la aplicación de las diferentes disposiciones que aseguraban la publicidad en el virreinato limense, mientras De Zaballa se servirá de una de esas disposiciones, las informaciones previas al matrimonio, para su análisis. Siegrist se centra en la excepción de esa publicidad, permitida por la Iglesia en determinados casos.

Latasa revisa la aplicación de la normativa tridentina de publicidad en las archidiócesis de Lima y Charcas en los siglos XVI al XVIII antes de la publicación de la Pragmática Sanción de 1776. La publicidad exigida por Trento para la validez, conllevó una serie de formalidades que aseguraran dicha publicidad en las distintas etapas del matrimonio, incluidas las informaciones previas. Pronto se incorporó esta normativa en Indias. Estudia la aplicación de ese ritual en el mundo andino, a través de la normativa conciliar y sinodal, así como a través de manuales de pastoral. Muestra las variedades en las distintas etapas, las informaciones, amonestaciones, desposorios y velaciones, así como las peculiaridades indianas, especialmente entre la población indígena. Por otra parte, a través del estudio canónico revela que las medidas que Trento impuso para asegurar la publicidad del matrimonio tenían una larga tradición iniciada en los siglos XII y XIII. También en Indias se dio ese anticipo en la importancia que el primer concilio limense, anterior a Trento, otorgó a las amonestaciones previas al matrimonio.

Por su parte Siegrist se centra en los matrimonios secretos que eludían la publicidad tridentina con la autorización de la autoridad eclesiástica. En su análisis hace referencia a los dos grandes virreinatos indianos, pero el estudio detallado se refiere a los matrimonios secretos celebrados en el siglo XVIII en Buenos Aires.

Siegrist dedica un apartado a analizar la legislación canónica así como la normativa a partir de 1741, cuando Benedicto XIV establece los pasos que debían seguir los matrimonios secretos. Aclara la casuística de este tipo de matrimonios, su nacimiento en Trento y los problemas que conllevó entre los poderes eclesiástico y secular pues, en determinadas circunstancias, el obispo casaba en secreto a quienes lo tenían prohibido por la Corona. El pulso de poder no se debió únicamente a la defensa de jurisdicción sobre los asuntos matrimoniales por parte de la Iglesia, sino a la salvación de sus fieles, que de no concederles esos matrimonios secretos corrían el peligro de caer en el concubinato. Durante los tres siglos de la Edad Moderna se llevaron a cabo matrimonios secretos con permiso del obispo. Este sigilo provocó su desconocimiento y trato desigual por la historiografía que prácticamente no ha tomado en cuenta este tipo de nupcias. El artículo abarca por vez primera la mayoría de las causas que existieron para realizar casamientos secretos en Buenos Aires. Entre las razones que llevaron a este tipo de matrimonios, no fue la falta de consentimiento paterno la principal, sino muy otras muy variadas, especialmente la falta de permisos 
de las autoridades a funcionarios de la administración de Indias y a militares para que pudieran casarse.

Los otros tres artículos se interesan por las consecuencias sociales y personales de la normativa tridentina. De Zaballa analiza el abundante mestizaje de la población indígena, a través de las informaciones de matrimonio surgidas durante tres de los recorridos de la visita episcopal de Aguiar y Seijas. Por otra parte los trabajos de Presta y Macías-Candau se centran en las causas y consecuencias de las demandas de divorcio y nulidad, especialmente para la mujer, en los siglos XVII y XVIII.

Hemos visto que entre los elementos dispuestos para asegurar la publicidad, se encontraban las informaciones o diligencias que se llevaban a cabo con los contrayentes antes de dar paso a las proclamas. Era un pequeño proceso que exigía la presentación de testigos por ambas partes para asegurar la libertad y la ausencia de impedimentos.

De Zaballa utiliza las informaciones o diligencias matrimoniales derivadas de una visita episcopal, lo que supone una selección natural de dichas informaciones. Como es sabido, uno de los objetivos de la visita era corregir las costumbres desordenadas de la feligresía y esto provocó que se hicieran visibles las parejas amancebadas, que por la presencia del obispo se vieron apremiadas a poner en orden su situación. Se trata de la visita de Aguiar y Seijas de parte del arzobispado de México en la segunda mitad del XVII. En este trabajo se exploran las posibilidades que ofrecen estas fuentes para descubrir los vínculos y relaciones sociales entre individuos de diferente calidad. Por una parte se trata de poner en valor la fuente y su especial carácter de ejercicio directo de la jurisdicción del obispo y, por otra, la realidad encontrada de un alto porcentaje de matrimonios exógenos entre la población indígena.

En los dos últimos artículos de este dossier se muestran algunos conflictos y demandas derivadas de la normativa sobre la patria potestad ${ }^{6}$ vigente en la Edad Moderna, así como el desafío de la misma por parte de alguna de las protagonistas buscando justicia para su situación.

Para el siglo XVII Presta revisa los crímenes y delitos perpetrados entre los esposos. Rastrea las voces femeninas a través de los documentos notariales y, provocadas por el maltrato, adulterio o engaño, sus solicitudes ante la justicia eclesiástica de divorcio o nulidad. A través de veintiún expedientes, de solicitud de divorcio y/o nulidad, hace un repaso a la condición de la esposa ante la justicia eclesiástica y fundamentalmente ante las costumbres sociales, que hacían muy difícil la vida de las mujeres una vez obtenida la sentencia de divorcio. Destaca la falta de libertad a favor de los intereses familiares, mostrando a la vez cómo en el centro de muchos de esos pleitos estará la defensa de la dote y el patrimonio de la mujer, importante para el enlace e imprescindible tras la separación.

Queda claro que el divorcio o separación tenía un camino difícil pero posible, mucho más ardua era la obtención de la nulidad. Macías y Candau abordan el matrimonio como lugar de conflictos donde el recrudecimiento de dichas situaciones, a veces graves, derivó en la solicitud de divorcio, demandas de nulidad eclesiástica o también el requerimiento de "vida maridable". Llevan a cabo una interesante y cuidada contextualización de las circunstancias históricas y la organización eclesiástica

6 Murillo 2004, Libro IV, Tit. 1, n.25. 
del arzobispado de Sevilla en el siglo XVIII y del derecho canónico del momento. Aunque centrado en la Sevilla del XVIII, sitúan los conflictos en comparación y contraste con otras regiones de España, Indias y también Europa.

Resaltan la influencia de la concepción patriarcal y de supeditación de la mujer -subrayan el sentimiento de "propiedad" por parte del marido- tanto en tipo de denuncias, como en las distintas consecuencias para uno y otra. Se trata de un estudio cuantitativo y cualitativo de los sectores sociales a los que afecta, analizando las diferencias entre los casos surgidos entre la élite o los ejemplos encontrados en los grupos populares. La mayor parte de los pleitos fueron de divorcio y abandono del hogar. Los casos estudiados, a diferencia de lo expuesto por Presta, muestran de forma plástica la violencia en el ámbito familiar y explicitan que el peligro por su vida fue lo que llevó a muchas mujeres a presentar la demanda de divorcio.

\section{REFERENCIAS BIBLIOGRÁFICAS}

Albani, Benedetta - Barbosa, Samuel - Duve, Thomas

(en prensa) "La Formación de Espacios Jurídicos Iberoamericanos (S. XVI-XIX): Actores, Artefactos E Ideas. Comentarios Introductorios (The Formation of Iberoamerican Legal Spaces (C. XVI-XIX): Actors, Artefacts and Ideas. Introductory comments)", Jahrbuch für Geschichte Lateinamerikas / Anuario de Historia de América Latina.

Latasa, Pilar

2008 "Publicidad y libertad en el matrimonio: autoridad paterna y dispensa de amonestaciones en lima 1600-1650", en USUNARIZ -GARCÍA BOURRELLIER (eds.), Padres e hijos en España y el Mundo Hispánico. Madrid. Visor Libros, pp. 53-67.

2016 'If they remained as mere words': Trent, Marriage, and Freedom in the Viceroyalty of Peru, Sixteenth to Eighteenth Centuries. The Americas: A Quarterly Review of Latin American History, Volume 73, Issue 01, January, pp. 13-38.

Murillo Velarde, Pedro

2004 Curso de Derecho canónico Hispano e Indiano. Trad. de Alberto Carrillo Cazares. Zamora - Michoacán. El Colegio de Michoacán - Facultad de Derecho, UNAM.

RAmos, Gabriela

2016 "Pastoral Visitations: Spaces of Negotiation in Andean Indigenous Parishes". The Americas: A Quarterly Review of Latin American History, Volume 73, Issue 01, January, pp. 39-57.

Traslosheros, Jorge E.

2014 Historia judicial eclesiástica de la Nueva España. Materia, método y razones. México. UNAM, Porrúa, Instituto de Investigaciones Históricas.

2016 "Introduction: Canon Law and its Practice in Colonial Latin America". The Americas: A Quarterly Review of Latin American History, Volume 73, Issue 01, January pp. 3-11.

Traslosheros, Jorge E. - Zaballa Beascoechea, Ana de (coords.)

2010 Los indios ante los foros de justicia religiosa en la Hispanoamérica Virreinal. México. Instituto de Investigaciones Históricas, UNAM.

Zaballa Beascoechea, Ana de

2016 "Promises and Deceits. Marriage among Indians in New Spain in the Seventeenth and Eighteenth Centuries". The Americas: A Quarterly Review of Latin American History, Volume 73, Issue 01, January, pp. 59-82. 